\title{
Non-nodulating Mutants of Pisum sativum (L.) cv. Sparkle
}

B. E. Kneen, N. F. Weeden, and T. A. LaRue

\begin{abstract}
Eleven pea mutants, displaying a greatly reduced number of root nodules or lacking such nodules completely, were obtained by screening the $\mathrm{M}_{2}$ progeny of mutagenized Pisum sativum cv. Sparkle. The mutant alleles conditioning the altered nodulation phenotypes were recessive to the wild-type alleles. Eight of the mutants possessed a normal growth habit except for the complete lack of nodules. Pairwise crosses among these mutants indicated that five distinct loci had been affected. The remaining three mutants formed few nodules and also had altered root or shoot growth habit. Each of these pleiotropic mutants was coded by a distinct gene. The eight genes identified are designated sym7, sym8, sym9, sym10, sym11, sym15, sym 16, and sym 17, signifying their involvement in the pea/Rhizobium symbiosis. The locations of most of these sym genes were determined by classical linkage mapping. The loci were distributed on at least five of the seven chromosomes.
\end{abstract}

The ability to form a symbiotic relationship with nitrogen-fixing bacteria of the genera Rhizobium or Bradyrhizobium is a characteristic of approximately $85 \%$ of legume species (Allen and Allen 1981). The nitrogen-fixing ability of soybean, alfalfa, and clover is of great practical importance because of the large areas planted with these crops. However, the species most often used in basic research on nitrogen fixation is the pea, Pisum sativum L., which has served as an experimental model since the earliest investigations (Fred et al. 1932). Pea is particularly useful for genetic studies because there are many well-defined marker loci that can be used to locate genes on the linkage map (Weeden et al. 1993).

Mutational analysis is one avenue to understanding the role of the plant in symbiotic nitrogen fixation. We have induced a large set of pea mutants that are defective in nodulation (Kneen et al. 1984, 1987, $1990 \mathrm{a}$ ), and are using them to characterize the symbiosis (sym) genes of the host plant. Except for nodulation, most of our mutants look normal (Kneen et al. 1984, 1990a). If provided with nitrate, their growth habit is no different than that of the normal nodulating parent Sparkle. Others, which we call pleiotropic mutants (Kneen et al. 1990b), are measurably different from their parent. Differences in plant habit cosegregate with nonnodulation after crosses to the parent or to tester lines. Additional nodulation mutants in pea have been isolated in other programs (Duc and Messager 1989; Engvild 1987; Jacobsen 1984). Most of these mutants fit into our first category, having few or no phenotypic effects except for the abnormal nodulation.

Nearly all the described nodulation mutants in pea have been demonstrated to display monogenic inheritance; yet only one, the naturally occurring sym-2, has been located to a specific region of the pea linkage map (Young 1985b). In the Rhizobium microsymbiont, the nod genes involved in nodule formation are tightly linked, and a similar organization might exist for the sym genes of the eukaryotic host. However, Young (1985a) suggested that many of the host's nodule-specific genes may have arisen by duplication of preexisting genes functioning in other processes. Nodule-specific sym genes would have evolved specialized controls appropriate to infection by rhizobia. But other sym genes, presumably existing before the symbiosis evolved, may still play a role in other tissues. Such a model predicts that the sym genes probably will not be clustered in the host's genome, some at least having arisen by independent gene duplication events.

In order to broaden our understanding of the genes involved in nitrogen fixation, we have partially characterized certain mutants that appear to be specific for nod- 
Table 1. Comparison of seedling dimensions among the parental line (Sparkle); a nonnodulating line with normal growth habit (R25), and the three plelotropic mutants (E151, R50, and R82) harvested 20 days after planting

\begin{tabular}{|c|c|c|c|c|c|}
\hline & Sparkle & R25 & E151 & R50 & $\mathbf{R} 82$ \\
\hline Plant height $(\mathrm{cm})$ & $14.8 \pm 2.5^{a}$ & $14.9 \pm 1.5^{\circ}$ & $13.3 \pm 2.1^{\circ}$ & $7.72 \pm 1.1^{b}$ & $8.04 \pm 0.9^{b}$ \\
\hline Third internode length $(\mathrm{cm})$ & $1.9 \pm 0.3^{a}$ & $1.9 \pm 0.3^{a}$ & $1.6 \pm 0.3^{b}$ & $1.2 \pm 0.3^{c}$ & $1.1 \pm 0.1^{c}$ \\
\hline Tap root length $(\mathrm{cm})$ & $27.2 \pm 3.8^{\circ}$ & $26.2 \pm 2.1^{\circ}$ & $22.2 \pm 2.6^{b}$ & $25.5 \pm 2.3^{\circ}$ & $7.20 \pm 1.3^{c}$ \\
\hline Lateral root mass (mg dry wt) & $137.0 \pm 37.0^{\circ}$ & $143.0 \pm 26.0^{\circ}$ & $42.0 \pm 11.0^{b}$ & $57.0 \pm 7.0^{b}$ & - \\
\hline
\end{tabular}

Plants were grown in a light room under a $16 \mathrm{~h} / 8 \mathrm{~h}$ day/night regime. Mean \pm standard deviation $(N=10)$ ${ }^{a-c}$ In the same row, means with different superscripts differ significantly $(P \leq .05)$. ule development and three additional mutants that affect other processes as well. In addition, we have used joint segregation analysis with standard marker loci in pea to determine the location of the genes on the pea linkage map.

\section{Materials and Methods}

Pea cv. Sparkle is a short statured, early maturing freezer pea from Rogers Bros. Seed Co. (Twin Falls, Idaho). Procedures for mutagenesis and screening the $\mathrm{M}_{2}$ progeny for nodulation have been described (Kneen and LaRue 1988). Stable nonnodulating lines E69, E140, and E151 were obtained by mutagenesis with ethylmethane sulfonate. Lines R19, R25, R50, $\mathrm{R} 72$, and $\mathrm{R} 82$ were induced with $\gamma$ radiation of moist seed. Mutant lines N12, N15, and N24 arose from treatment of dry seed with fast neutrons. Each $\mathrm{M}_{2}$ plant was taken through several generations of selfing to ensure homozygosity in each sym line.

For growth measurement of seedlings, we measured the length of the root and of the epicotyl and the dry weight of lateral roots. For measuring internode lengths, the cotyledonary node is considered node 0 and the bract is node 1 . Thus, internode 3 is that below node 3 bearing the first leaf. In mapping experiments, we scored progeny of E151, R50, and R72 for length of lateral roots rather than presence or absence of nodules.

Mutants were crossed with each other and with their parent Sparkle or with $\mathrm{cv}$. Rondo. We planted $F_{1}$ and $F_{2}$ seeds in vermiculite in individual conical pots (conetainers), inoculated with Rhizobium leguminosarum $128 \mathrm{C} 53$, and irrigated with nutrient solution at planting and with water thereafter (Kneen and LaRue 1988). We harvested plants at 3-4 weeks after seeding and scored for nodulation.

Mutant lines were crossed with one or more lines held at the Department of Horticultural Sciences, Cornell University. These include the primitive cv. Afghanistan (Kneen and LaRue 1984b) and the tester lines NGB1446 (courtesy of Dr. S. Blixt, Nordic Genebank), A1078-234 (Weeden and Marx 1984), A783-161, and A583-139 (Marx GA, unpublished), and Fast, Slow, and NFST (Weeden NF, unpublished).

Numerous morphological markers were scored in the progeny of several crosses used to map the sym genes. These include $a$ (white flowers), $i$ (green cotyledons), $n$ (thick pod wall), $d$ (leaf axil anthocyanin), af (leaflets converted to tendrils), oh (brownish testa), $w b$ (waxless stipules), st (lanceolate stipules), le (dwarf), was (waxless stem), g $\rho$ (yellow pod), Fs (violet spots on testa), Pl (black hilum), Arg (silver foliage), $t l$ (tendrils converted to leaflets), and $r$ (wrinkled seeds) (Blixt 1974). The seed characters $i, n, o h, F s, P l$, and $r$ were scored on mature seeds after $F_{2}$ plants were harvested. All other tests were scored on $\mathrm{F}_{2}$ plants.

Leaf and root extracts were used for isozyme analysis. Tissues were extracted in cold buffer containing $0.1 \mathrm{M}$ Tris- $\mathrm{HCl}, \mathrm{pH}$ $8.0,5 \%$ soluble polyvinyl pyrrolidone, $5 \%$ glycerol, and $0.5 \%$ Triton X-100. For leaf extracts, we added $14 \mathrm{mM} \beta$-mercaptoethanol to the extraction buffer immediately before use. Enzyme systems examined included acid phosphatase (two loci), am-
Table 2. Comparison of seedling dimensions among the parental line (Sparkle), a nonnodulating line with normal growth habit (R25), and the three pleiotropic mutants (E151, R50, and R82)

\begin{tabular}{llrrrr} 
& Sparkle & \multicolumn{1}{c}{ R25 } & E151 & \multicolumn{1}{c}{ R50 } & R82 \\
\hline Plant height $(\mathrm{cm})$ & $29.1 \pm 1.1^{a}$ & $26.5 \pm 2.8^{\circ}$ & $28.1 \pm 2.1^{\circ}$ & $15.1 \pm 1.0^{b}$ & $8.1 \pm 0.7^{\mathrm{c}}$ \\
Third internode length $(\mathrm{cm})$ & $10.3 \pm 0.7^{a}$ & $9.8 \pm 0.7^{a, b}$ & $8.3 \pm 1.1^{b}$ & $6.2 \pm 0.8^{c}$ & $3.1 \pm 0.8^{d}$ \\
\hline
\end{tabular}

Plants were grown in continuous darkness and harvested 11 days after planting. Mean \pm standard deviation $(N$ $=10$ ).

${ }_{a-d}$ In the same row, means with different superscripts differ significantly $(P \leq .05)$. ylase (one locus), aspartate aminotransferase (three loci), fluorescent esterase (three loci), fumarase (one locus), fructose 1,6-diphosphate aldolase (one locus), beta-galactosidase (two loci), isocitrate dehydrogenase (one locus), leucine aminopeptidase (two loci), $N$-acetyl- $\beta$-glucosaminidase (one locus), phosphoglucomutase (two loci), 6-phosphogluconate dehydrogenase (two loci), and shikimate dehydrogenase (one locus). The methods for resolving and detecting the allozymes have been described by Weeden and Marx (1987) and Wendel and Weeden (1989).

In total, approximately $75 \%$ of the known linkage map for pea lay within $20 \mathrm{cM}$ of the markers used in this study (Weeden et al. 1993). We used the computer program LINKAGE-1 (Suiter et al. 1983) to analyze segregation and linkage.

\section{Results}

In every case, $F_{1}$ plants produced from crosses of sym lines with the nodulating parent Sparkle displayed a normal nodulation phenotype. $F_{2}$ progeny segregated $3: 1$ nodulated/nonnodulated, indicating that nonnodulation was conditioned in each case by a recessive gene.

Diallel crosses among the nonnodulating mutants with otherwise normal phenotypes revealed five complementation groups, based on the nonnodulation phenotype of $F_{1}$ progeny. Reciprocal crosses of R19, R25, and E140 produced nonnodulating $F_{1}$ plants, as did reciprocal crosses of E69 and N12. Reciprocal crosses of E69, R25, R72, N15, and N24 produced normally nodulating $F_{1}$ progeny. These loci and the lines defining them are designated sym7 (line E69), sym8 (line R25), sym9 (line R72), sym10 (line N15), and symll (line N24).

Each line homozygous for one of the pleiotropic mutations (affecting characters in addition to nodulation), when crossed with cv. Sparkle or cv. Rondo, produced $F_{1}$ plants with normal phenotypes. The $F_{2}$ populations cosegregated $3: 1$ nodulated and normal-rooted to nonnodulated with short lateral roots (data not shown). The recessive genes and the lines defining the pleiotropic phenotypes were designated sym 15(line E151), sym 16 (line R50), and sym 17 (line R82).

Table 1 reports some of the dimensions of these three short-root plants harvested after growth in light rooms for 3 weeks. Table 2 lists dimensions of seedlings harvested after 11 days growth in continuous darkness. The three mutants are com- 
pared with the normal parent Sparkle and with R25 (sym8), which is representative of nonnodulating mutants with otherwise normal growth habit (Markwei and LaRue 1992). The data indicate that R25 (sym8) does not differ markedly from the parent Sparkle; however, the three pleiotropic mutants differ significantly from Sparkle and from each other.

The upper laterals of E151 (sym15) appear normal, but lower ones are short and thin. The overall height of the epicotyl is scarcely different from normal, but the length of the third internode is significantly less than normal. Leaves are normal; nodulation is rare.

R50 ( $s y m$ 16) has few laterals, and they are thicker than those of Sparkle. All the internodes are shorter, making the overall height of R50 less than Sparkle or R25. Leaves are normal sized, but pale and with slightly raised veins. Nodules are rarely seen.

R82 (sym 17) has thick, short primary and lateral roots. The phenotype resembles the thick, short root (tsr) morphology induced on vetch by some strains of $R$. leguminosarum (Zaat et al. 1989). There are few nodules, and they appear on the lateral roots near the primary root. The epicotyl is short; leaves are small and dark green. Pods are wrinkled (Lee and LaRue 1992).

Six of the eight sym genes displayed clear deviations from random assortment with specific morphological or allozyme marker loci (Table 3). The gene sym 7 showed linkage to Lap-l and st on linkage group 3. Relative recombination rates and the accepted map distance between $S t$ and Lap- $I$ of 20-30 cM suggest that sym 7 is located between the two marker loci, slightly closer to St. Sym 8 mapped close to $\mathrm{Arg}$ and $\mathrm{Pl}$. Relative map distances suggest a gene order of Pl-Arg-Sym8.

In the $\mathrm{F}_{2}$ progeny from one cross (R72 $\times$ A583-139), sym9 displayed complete linkage with $r$, a marker gene on linkage group 5. However, we could not confirm this linkage in $F_{2}$ populations from other crosses. Preliminary results from cytological studies indicate that line A583-139 differs from the Sparkle karyotype by a reciprocal translocation involving chromosome 5 and an unidentified linkage group (Temnykh S, Weeden NF, and LaRue TA, unpublished). In a different $\mathrm{F}_{2}$, sym9 displayed weak linkage with $n$ on linkage group 4 (Table 3). However, at present the location of sym 9 is best regarded as being in the $25 \%$ of the genome more than $20 \mathrm{cM}$ from the markers analyzed.

Table 3. Jolnt segregation data for sym genes and marker loci of Pisum sativum

\begin{tabular}{|c|c|c|c|c|c|c|c|c|c|}
\hline \multirow[b]{2}{*}{ Crosses, loci } & \multirow[b]{2}{*}{$N$} & \multicolumn{6}{|c|}{ No. plants with designated phenotype ${ }^{a}$} & \multirow[b]{2}{*}{$p^{\infty}$} & \multirow{2}{*}{$\begin{array}{l}\text { Recombination } \\
\text { fraction }{ }^{e}\end{array}$} \\
\hline & & $+/ 1$ & $+/ h$ & $+/ 2$ & $-/ 1$ & $-/ \mathrm{h}$ & $-/ 2$ & & \\
\hline \multicolumn{10}{|l|}{ A1078-234 × E69 } \\
\hline $\begin{array}{l}\text { Sym7/Lap-1 } \\
\text { Sym7/St }\end{array}$ & $\begin{array}{l}45 \\
43\end{array}$ & $\begin{array}{r}12 \\
8\end{array}$ & $-^{\alpha}$ & $\begin{array}{r}2 \\
25\end{array}$ & $\begin{array}{l}0 \\
0\end{array}$ & $\begin{array}{l}2 \\
-\end{array}$ & $\begin{array}{l}14 \\
10\end{array}$ & $\begin{array}{c}<.0001 \\
.08\end{array}$ & $\begin{array}{l}8 \pm 4 \\
1 \pm 15\end{array}$ \\
\hline \multicolumn{10}{|l|}{$\mathrm{A} 73-91 \times \mathrm{E} 69$} \\
\hline $\begin{array}{l}\text { Sym7/Lap-1 } \\
\text { Sym7/St }\end{array}$ & $\begin{array}{l}29 \\
29\end{array}$ & $\begin{array}{l}7 \\
9\end{array}$ & 10 & $\begin{array}{r}2 \\
10\end{array}$ & $\begin{array}{l}0 \\
0\end{array}$ & 2 & $\begin{array}{r}8 \\
10\end{array}$ & $\begin{array}{l}<.001 \\
<.01\end{array}$ & $\begin{aligned} 13 & \pm 7 \\
1 & \pm 19\end{aligned}$ \\
\hline \multicolumn{10}{|l|}{$\mathrm{A} 783-161 \times \mathrm{R} 25$} \\
\hline $\begin{array}{l}\text { Sym8/Arg } \\
\text { Sym8/Pl } \\
\text { Arg/Pl }\end{array}$ & $\begin{array}{r}109 \\
48 \\
48\end{array}$ & $\begin{array}{l}59 \\
31 \\
31\end{array}$ & $\frac{-}{-}$ & $\begin{array}{l}6 \\
2 \\
0\end{array}$ & $\begin{array}{l}3 \\
0 \\
0\end{array}$ & $\frac{-}{-}$ & $\begin{array}{l}41 \\
15 \\
17\end{array}$ & $\begin{array}{l}<.0001 \\
<.0001 \\
<.0001\end{array}$ & $\begin{aligned} 7 & \pm 10 \\
4 & \pm 14 \\
<5 & \pm \text { undefined }\end{aligned}$ \\
\hline \multicolumn{10}{|l|}{$\mathrm{R} 72 \times \mathrm{A} 583-139$} \\
\hline Sym9/R & 43 & 13 & - & 0 & 0 & - & 30 & $<.0001$ & $<5 \pm$ undefined \\
\hline \multicolumn{10}{|c|}{$\mathrm{R} 72 \times \mathrm{A} 1078-234$} \\
\hline Sym $9 / N$ & 35 & 17 & - & 8 & 10 & - & 0 & $<.05$ & $1 \pm 17$ \\
\hline \multicolumn{10}{|c|}{ N15 $\times$ Afghanistan } \\
\hline Symlo/l & 38 & 28 & - & 2 & 1 & - & 7 & $<.0001$ & $9 \pm 16$ \\
\hline \multicolumn{10}{|l|}{$\mathrm{N} 24 \times$ Slow } \\
\hline $\begin{array}{l}\text { Sym1l/Skdh } \\
\text { Sym11/Est-2 } \\
\text { Sym11/Aldo }\end{array}$ & $\begin{array}{l}36 \\
36 \\
36\end{array}$ & $\begin{array}{r}6 \\
12 \\
8\end{array}$ & $\begin{array}{l}20 \\
14 \\
14\end{array}$ & $\begin{array}{l}5 \\
5 \\
9\end{array}$ & $\begin{array}{l}0 \\
0 \\
0\end{array}$ & $\begin{array}{l}0 \\
0 \\
3\end{array}$ & $\begin{array}{l}5 \\
5 \\
2\end{array}$ & $\begin{array}{c}<.001 \\
<.001 \\
\quad \text { NS }\end{array}$ & $\begin{array}{l}15 \pm 7 \\
17 \pm 8 \\
42 \pm 10\end{array}$ \\
\hline \multicolumn{10}{|l|}{ Slow $\times$ E151 } \\
\hline Sym15/Aldo & 28 & 7 & 12 & 3 & 0 & 1 & 5 & $<.01$ & $15 \pm 7$ \\
\hline \multicolumn{10}{|l|}{ Fast $\times \mathrm{E} 151$} \\
\hline Sym I5/Aat-m & 24 & 5 & 11 & 2 & 0 & 0 & 6 & $<.001$ & $8 \pm 6$ \\
\hline \multicolumn{10}{|l|}{ NGB1446 $\times$ E151 } \\
\hline Sym 15/Amy & 57 & 12 & 28 & 1 & 1 & 3 & 12 & $<.0001$ & $10 \pm 4$ \\
\hline \multicolumn{10}{|l|}{ Fast $\times \mathbf{R} 50$} \\
\hline $\begin{array}{l}\text { Sym16/Pgd-c } \\
\text { Sym 16/Nag }\end{array}$ & $\begin{array}{l}59 \\
38\end{array}$ & $\begin{array}{r}11 \\
7\end{array}$ & $\begin{array}{l}25 \\
17\end{array}$ & $\begin{array}{l}3 \\
1\end{array}$ & $\begin{array}{l}1 \\
1\end{array}$ & $\begin{array}{l}3 \\
1\end{array}$ & $\begin{array}{l}16 \\
11\end{array}$ & $\begin{array}{l}<.0001 \\
<.0001\end{array}$ & $\begin{array}{r}12 \pm 4 \\
9 \pm 5\end{array}$ \\
\hline \multicolumn{10}{|l|}{ Slow $\times$ R50 } \\
\hline $\begin{array}{l}\text { Sym 16/Nag } \\
\text { Sym 16/ACp-I }\end{array}$ & $\begin{array}{l}42 \\
42\end{array}$ & $\begin{array}{l}15 \\
19\end{array}$ & $\begin{array}{l}19 \\
14\end{array}$ & $\begin{array}{l}1 \\
2\end{array}$ & $\begin{array}{l}0 \\
0\end{array}$ & $\begin{array}{l}2 \\
2\end{array}$ & $\begin{array}{l}5 \\
5\end{array}$ & $\begin{array}{l}<.0001 \\
<.0001\end{array}$ & $\begin{array}{r}9 \pm 5 \\
13 \pm 5\end{array}$ \\
\hline \multicolumn{10}{|l|}{ R8 $2 \times$ NFST } \\
\hline Sym 17/Prx-3 & 50 & 11 & 3 & 2 & 9 & 16 & 9 & $<.05$ & $29 \pm 7$ \\
\hline
\end{tabular}

${ }^{a}$ Phenotype designations: $+=$ nodulating; $-=$ nonnodulating; $1=$ female parent; $h=$ heterozygous; $2=$ male parent.

${ }^{\circ}$ Probability $(P)$ based on 9:3:3:1 or 3:6:3:1:2:1 phenotypic ratios for random assortment

c Recombinant fraction \pm standard error.

"No plants expected in categories marked "-.".

NS, not significant.

On chromosome 1, sym 10 was mapped near $I$, the locus responsible for the green versus yellow cotyledon color. There were no other markers available in this region, and we did not determine on which side of $I$ this nodulation gene is located. The relative map distances of $s y m / l$ from $S k d h$ and Est-2 as well as its lack of linkage to Aldo indicate that $s y m l l$ is on the side of Skdh opposite Est-2 on chromosome 7.

The pleiotropic mutant sym 15 also mapped to chromosome 7. This gene could be placed between Aat-m and Amy, a location 30-40 cM from symll. The inheritance of sym 16 correlated with markers on chromosome 5, Nag being the locus displaying tightest linkage to this mutant. Finally, in crosses with Slow and Fast, sym $/ 7$ assorted independently from all marker loci (data not shown), but in the NFST $\times$ R82 progeny this gene exhibited loose linkage (approximately $30 \mathrm{cM}$ ) to $\operatorname{Pr} x-3$ (Table 3 ). This linkage suggests $s y m / 7$ may be on linkage group 6 .

\section{Discussion}

We have obtained mutants of pea cv. Sparkle that form few or no nodules. If the plants are grown with adequate nitrogen in the substrate, they grow and set viable seed. Some of the mutants have shortened roots or shoots; others appear normal. Each of the mutants is conditioned by a single recessive gene, as is the case for every other induced nonnodulating pea mutant presently described (Duc and Messager 1989; Engvild 1987; Jacobsen 1984; Kneen et al. 
1984; Kneen and LaRue 1988). However, the study presented here is the first to make a concerted effort to Jocalize these mutants.

As has been shown previously for sym 5 in pea (Kneen and LaRue 1988) and sym3 in sweet-clover (Miller et al. 1991), it is possible to produce mutants at the same locus with different mutagens. Mutations at $s y m 7$ and $s y m 8$ were obtained with the chemical mutagen EMS, as well as with a physical mutagen, $\gamma$ irradiation or fast neutrons. The linkage relationships we observed among marker loci were, in nearly every case, those predicted by the standard linkage map. Thus, the mutations did not involve translocations or large inversions.

The mutant sym genes are, in general, not closely linked to each other or to previously mapped genes involved in the nodulation process. We find $s y m 7$ and $s y m 8$ on chromosomes 3 and 6 , respectively. Sym 9 is not close to any of the marker loci used in this study, although it does appear to be close to the translocation breakpoint in the R72 $\times$ A583-139 progeny. Though sym 10 is on chromosome 1 , near $I$, this locus is far from the previously mapped sym 2 . That gene, which conditions strain specific nodulation (Kneen and LaRue $1984 \mathrm{~b}$ ), is linked to $I d h$ (Kneen et al. 1984) and $D$ (Young 1985b) on chromosome 1 . Linkage of sym 11 to $S k d h$ and Est-2 places it on chromosome 7. (This portion of the genome was previously assigned to chromosome 2 [Blixt 1974].) E.135, a phenotypically different mutant with nonfixing nodules, is conditioned by sym 13 , which also is in this region (Kneen et al. 1990a).

The dispersal of the three pleiotropic mutations on three chromosomes also appears to confirm the wide distribution of the sym genes. Sym 15 is located on the same linkage group as sym 11 , but is over $30 \mathrm{cM}$ from the latter. sym 16 is the only known gene on linkage group 5 that affects nodulation. Although the position of sym 17 is uncertain, the possibility exists that it may be close to sym 8 on chromosome 6 . As is the case with sym9, sym 17 is not close to the sym genes on linkage groups 1,3 , 5 , or 7 as demonstrated by its independent assortment with marker genes on these linkage groups. This pattern of nonlinkage is similar to that of other functionally related nuclear genes such as those involved in chloroplast biochemistry, anthocyanin biosynthesis, or carbohydrate metabolism (Weeden et al. 1993; Weeden and Wendel 1989). In the microsymbiont $R$. leguminosarum, the nod and fix genes for nodule formation and nitrogen fixation are clustered, facilitating study of the bacterial genetics. Apparently, Nature did not package the plant's sym genes as conveniently.

Sym 16 is the only pleiotropic mutant that maps relatively close to a previously described gene affecting root architecture. Plants homozygous for the gene coh possess stubby roots and short internodes similar to sym $16 /$ sym 16 plants. However, coh/coh plants nodulate normally and possess a slightly different root morphotype from sym 16 plants (data not presented). The precise positions of sym 16 and coh are uncertain. Previous investigations on the relative positions of $\mathrm{Pgd}-\mathrm{c}, \mathrm{Nag}$ and $A c p-l$ indicate that $P g d-c$ and $A c p-I$ are approximately $20 \mathrm{cM}$ apart, with $\mathrm{Nag}$ approximately halfway between them (Weeden and Marx 1987). The data presented in Table 3 place sym 16 nearly equidistant from $P g d-c$ and $A c p-1$ (12 and $13 \mathrm{cM}$, respectively). In both progenies, sym 16 is 9 cM from Nag but on a different side in each progeny. Both acid phosphatase and 6-phosphogluconate dehydrogenase give well-resolved variation, whereas $\mathrm{N}$-acetyl$\beta$-glucosaminidase phenotypes are often faint and blurred. Hence, we suspect that certain NAG phenotypes were incorrectly scored and that sym 16 is actually within 5 cM of Nag. Although coh has not been mapped relative to the isozyme loci, comparative distances to morphological markers such as $F$ s indicate that coh also will be near Nag (Blixt 1974)

Pleiotropic symbiosis mutants have been described before. We have previously described $b r z$, a mutant gene in Sparkle that causes leaf necrosis and excessive iron uptake as well as decreased nodulation (Kneen et al. 1990b). In chickpea, a nonnodulating mutant also has wrinkled pods (Davis et al. 1986), as does sym 17 (Lee and LaRue 1992). It is possible that all the pleiotropic effects are produced by mutations tightly linked to the sym loci rather than direct effects of the sym mutations. A minor inversion might affect the expression of several genes within the inversion and yet appear to be inherited as a single mutation as a result of suppression of recombination within the inversion. However, we believe it unlikely that all the pleiotropic effects of the sym mutants are caused by tightly linked genes. We are continuing to analyze these mutants with respect to both their role in nodule formation and what they might reveal about the development of the root. Hirsch (1992) has reviewed the evidence that the nodule is a modified lateral root and that some genes may be expressed in both structures. As there have been few attempts at obtaining root mutants (Zobel 1975), we suspect that the mutants we have identified in pea may be important tools for both subjects.

\section{References}

Allen $O N$ and Allen EK, 1981. The leguminosae. Madison: University of Wisconsin Press.

Blixt S, 1974. The pea. In: Handbook of genetics, vol. 2 (King RC, ed). New York: Plenum Press; 181-221.

Davis TM, Foster KW, and Phillips DA, I986. Inheritance and expression of three genes controlling root nodule formation in chick pea. Crop Sci 26:719-723.

Duc $\mathrm{G}$ and Messager A, 1989. Mutagenesis of pea ( $P i$ sum sativum $\mathrm{L}$.) and the isolation of mutants for nodulation and nitrogen fixation. Plant Sci 60:207-213.

Engvild KJ, 1987. Nodulation and nitrogen fixation mutants of pea, Pisum sativum. Theor Appl Genet 74:711713

Fred EB, Baldwin IL, and McCoy E, 1932. Root nodule bacteria and leguminous plants. Madison: University of Wisconsin Press.

Hirsch AM, 1992. Developmental biology of legume nodulation. New Phytol 122:211-237.

Jacobsen E, 1984. Modification of symbiotic interaction of pea (Pisum sativum L.) and Rhizobium leguminosarum by induced mutations. Plant Soil 82:155167

Kneen BE and LaRue TA, 1984a. Nodulation resistant mutant of Pisum sativum. J Hered 75:238-240.

Kneen BE and LaRue TA, 1984b. Peas (Pisum sativum L.) with strain specificity for Rhizobium leguminosarum. Heredity 52:383-389.

Kneen BE and LaRue TA, 1988. Induced symbiosis mutants of pea (Pisum sativum) and sweet clover (Melilotus alba annua). Plant Sci 58:177-182.

Kneen BE, LaRue TA, Hirsch AM, Smith CA, and Weeden NF, 1990a. Sym 13, a gene conditioning ineffective nodulation in Pisum sativum. Plant Physiol 94:899-905.

Kneen BE, LaRue TA, and Weeden NF, 1984. Genes reported to affect symbiotic nitrogen fixation by peas. Pisum Newslett 16:31-34

Kneen BE, LaRue TA, Welch RM, and Weeden NF, 1990b. Pleiotropic effects of brz. A mutation in Pisum sativum (L.) cv. "Sparkle" conditioning decreased nodulation and increased iron uptake and leaf necrosis. Plant Physiol 93:717-722.

Kneen BE, vam Vikites D, and LaRue TA, 1987. Induced symbiosis mutants of Pisum sativum. In: Molecular genetics of plant-microbe interactions (Verma DPS and Brisson N, eds), Dordrecht: Martinus Nijhof; 79-84.

Lee KL and LaRue TA, 1992. Pleiotropic effects of sym 17. A mutation in Pisum sativum L. cy. "Sparkle" causes decreased nodulation, altered root and shoot growth and increased ethylene production. Plant Physiol 100: 1326-1333.

Markwei CM and LaRue TA, 1992. Phenotypic characterization of sym 8 and sym 9, two genes conditioning non-nodulation in Pisum sativum "Sparkle." Can J Microbiol 38:548-554.

Miller JE, Viands DR, and LaRue TA, 1991. Inheritance of non-nodulating mutants of sweet clover, Melilofus alba annua (Descr.) Crop Sci 31:948-952.

Suiter KA, Wendel JF, and Case JS, 1983. LINKAGE-1: a PASCAL computer program for the detection and analysis of genetic linkage. J Hered 74:203-204.

Weeden NF, Ambrose M, and Swiecicki W, 1993. Pisum sativum, pea. In; Genetic maps, 6th ed (O'Brien SJ, ed) Cold Spring Harbor, New York: Cold Spring Harbor Press; 6.24-6.34. 
Weeden NF and Marx GA, 1984. Chromosomal locations of twelve isozyme loci in Pisum sativum. J Hered 75:365-370.

Weeden NF and Marx GA, 1987. Further genetic anal ysis and linkage relationships of isozyme loci in the pea. Confirmation of the diptoid nature of the genome. J Hered 78:153-159.

Weeden NF and Wendel JF, 1989. Genetics of plant isozymes. In: Isozymes in plant biology (Soltis DE and Soltis PS, eds). Portland, Oregon: Dioscorides Press; $46-72$.
Wendel JF and Weeden NF, 1989. Visualization and interpretation of plant isozymes. In: Isozymes in plant biology (Soltis DE and Soltis PS, eds). Portland, Oregon: Dioscorides Press; 5-45.

Young JPW, 1985a. The phylogeny of the Rhizobium symbiosis. In: Analysis of the plant genes involved in the legume-rhizobium symbiosis (Marcellin R, ed). Paris: OECD; 12-19.

Young JPW, 1985b. Linkage of sym 2, the symbiotic specificity locus of Pisum sativum. J Hered 76:207-208.
Zaat SAJ, Van Brussel AAN, Tak T, Lugtenberg BJJ, and Kijne JW, 1989. The ethylene inhibitor aminoethoxyvinyl glycine restores normal nodulation by Rhizobium leguminosarum biovar viciae on Vicea sativa subsp. nigra by suppressing the "thick and short roots" phenotype. Planta 177:141-150.

Zobel RW, 1975. The genetics of root development. In The development and function of roots (Torrey JG and Clarkson D, eds). New York: Academic Press; 261-275. 